\title{
Effects of straw returning on rice growth and yield under water-saving irrigation
}

\author{
Qi Wei ${ }^{1,2}$, Junzeng Xu ${ }^{1,3^{*}}$, Lu Sun ${ }^{3}$, Haiyu Wang \\ 'Hohai University, State Key Laboratory of Hydrology-Water Resources and Hydraulic Engineering, Nanjing 210098, China. \\ ${ }^{2}$ Hohai University, College of Water Conservancy and Hydropower Engineering, Nanjing 210098, China. \\ ${ }^{3}$ Hohai University, College of Agricultural Engineering, Nanjing 210098, China.'Corresponding author (xjz481@ @hhu.edu.cn).
}

Received: 6 July 2018; Accepted: 13 November 2018; doi:10.4067/S0718-58392019000100066

\begin{abstract}
Straw returning (SR) is an important means of straw utilization, which has been tested and is helpful for improving soil fertility and crop production. However, the effects of SR on plant growth and yield of paddy rice (Oryza sativa $\mathrm{L}$. subsp. japonica Kato) under water-saving irrigation (WSI) are rarely investigated. In the 2015 and 2016 rice seasons, field experiments were conducted with four treatments, namely controlled irrigation with conventional fertilization (CI$\mathrm{CF}$ ), controlled irrigation with straw returning (CI-SR), flooding irrigation with conventional fertilization (FI-CF), and flooding irrigation with straw returning (FI-SR). The objective of the present study was to investigate the response of plant height, number of tillers, biomass, and yield to SR and irrigation management. Results indicated that SR enhanced rice yield on average by $7.9 \%$ and $7.5 \%$ and improved irrigation water use efficiency (IWUE) by $6.3 \%$ and $8.3 \%$ in 2015 and 2016, respectively. The CI-SR combination significantly increased IWUE compared with FI-CF. These results suggested that SR could offset the inhibition of rice growth caused by CI, and the CI-SR combination could be an effective measure to enhance soil fertility, maintain the rice field, and increase IWUE. Furthermore, rice growth (plant height, number of tillers, and biomass) was slightly inhibited by SR during the first $20 \mathrm{~d}$ of the rice season, but increased after the jointing stage (approximately $40 \mathrm{~d}$ after transplanting). This implied that diverting some top-dressed chemical $\mathrm{N}$ fertilizer into basal application may be necessary for fertilizer management to better meet crop nutrient uptakes in rice fields with SR application, especially with CI.
\end{abstract}

Key words: Controlled irrigation, flooding irrigation, irrigation water use efficiency, Oryza sativa, soil available nutrients, straw returning, yield components.

\section{INTRODUCTION}

Crop straw is a large universal organic agricultural waste resource, which has exceeded 700 million tons per year in China and accounts for more than 25\% of global straw resources (Lal, 2005; Yang et al., 2014). However, most crop straw is directly burned and only a small portion (2\%-5\%) is used as organic fertilizer for agricultural production (Yang et al., 2014), and it has inevitably caused wasted resources and environmental pollution (Thuy et al., 2008; Ge et al., 2013). Meanwhile, crop straw is a sustainable agricultural resource; it usually plays a positive role in maintaining soil fertility and improving soil characteristics (Liu et al., 2014a; Abrantes et al., 2018). Straw resources have been of greater interest in recent years, and their rational use and influence on agricultural production are key issues.

Straw returning (SR) is a direct and effective means of straw utilization; it not only offers an opportunity to consume crop straw, but also supplies organic matter (OM) for farmland and reduces the amount of chemical fertilizer (Sfez et al., 2017). Previous studies have researched the impact of SR on soil structure and OM decomposition, indicating that it is helps to decrease soil bulk density, increases soil water stable aggregates (Liu et al., 2014a), and improves soil organic 
matter (SOM) (Curtin and Fraser, 2003). Many studies have been concerned with the influence of SR on crop growth and yield (Asten et al., 2005; Kaur and Mahal, 2017; Wang et al., 2018). For paddy fields, previous studies have investigated the impact of the amounts, application time, and burial depth of SR on rice (Oryza sativa L.) growth and yield (Beutler et al., 2017; Mi et al., 2018). It has been demonstrated that SR at the rate of $<7.5 \mathrm{tha}^{-1}$ can enhance rice plant height, number of tillers, and biomass production in the middle or late growth stages (Thuy et al., 2008; Han et al., 2012). It can also reduce rice effective panicles per unit area, while number of spikelets per panicle, ripening rate, and rice yield can increase (Xu et al., 2015). The appropriate amount and burial depth of SR to increase rice yield have been at approximately $9 \mathrm{t} \mathrm{ha}^{-1}$ and 5-8 cm, respectively (Curtin and Fraser, 2003; Zhang et al., 2015). Although there is adequate information about the effects of SR on rice growth and yield, most studies have researched its impact under flooding irrigation (FI).

With irrigation water shortage on the increase and food security issues in China, water-saving irrigation (WSI) techniques (such as alternative irrigation, AI and controlled irrigation, $\mathrm{CI}$ ) are being widely used in paddy fields (Bouman et al., 2007; Xu et al., 2017; Yang et al., 2018). Under WSI irrigation, soil moisture is different than under FI. This definitely leads to remarkable changes in soil aeration, soil microorganism properties, and thus crop straw decomposition, which could greatly influence rice growth and yield. However, only a few studies (Zhang et al., 2014; Zhao, 2016; Zhao et al., 2018) are dedicated to investigating the effects of SR on soil properties or rice growth under WSI conditions, and their conclusions are sometimes contrary one with the other. For example, Zhao (2016) demonstrates that SR under AI irrigation is more beneficial to reduce soil bulk density, increase soil total $\mathrm{N}$ and $\mathrm{OM}$, and improve $\mathrm{N}$ utilization compared with FI, which usually leads to an increase in the number of spikelets per panicle, rice biomass, and yield. Zhang et al. (2014) have researched rice growth and yield under different irrigation (FI and AI) and straw utilization (returning or mulching) methods. They have indicated that AI irrigation can effectively mitigate the negative effects (usually reduced soil $\mathrm{pH}$ and soil aeration and increased reductive toxic substances) of SR and increase rice plant height, biomass production, and yield, independently of SR or straw mulching conditions. Zhao et al. (2018) have investigated rice growth and yield from SR in paddy fields with different irrigation regimes (FI, AI, and CI); they found that WSI (AI and SI) reduces rice plant height and yield (except for AI) compared with FI, although it usually accelerates SOM decomposition in straw and increases the number of tillers at the middle growth stage. Crop straw is an important source of SOM and is significantly affected by soil moisture. Therefore, rice WSI technologies should be applied in combination with SR to reveal the impact it has on rice growth and yield, especially compared with FI and conventional fertilization (CF) conditions. However, such combined applications have rarely been investigated in previous research studies.

A 2-yr field experiment was conducted in a paddy field with different water and fertilizer management. The objectives of the study were to investigate the impact of SR on crop growth under WSI as well as analyze and compare the effect of water and fertilizer management on rice yield and irrigation water use efficiency.

\section{MATERIALS AND METHODS}

\section{Experimental design}

The experiment was conducted from June 2015 to November 2016 in rice fields at the Kunshan Irrigation and Drainage Experimental Station (31 $15^{\prime} 15^{\prime \prime}$ N, $121^{\circ} 57^{\prime} 43^{\prime \prime}$ E) in Tai Lake region, Jiangsu Province, China. The study area has a subtropical monsoon climate with an average annual air temperature of $15.5^{\circ} \mathrm{C}$ and average annual precipitation of $1097.1 \mathrm{~mm}$. The top $(0-18 \mathrm{~cm})$ soil is clay with $21.8 \mathrm{~g} \mathrm{~kg}^{-1} \mathrm{OM}, 1.8 \mathrm{~g} \mathrm{~kg}^{-1}$ total $\mathrm{N}(\mathrm{TN}), 1.4 \mathrm{~g} \mathrm{~kg}^{-1}$ total P (TP), $20.9 \mathrm{~g} \mathrm{~kg}^{-1}$ total $\mathrm{K}(\mathrm{TK})$, and $\mathrm{pH} 7.4$ (1:2.5, soil:water). The mean saturated soil water contents for the $0-20,0-30$, and $0-40 \mathrm{~cm}$ layers were $54.4 \%(\mathrm{v} / \mathrm{v}), 49.7 \%(\mathrm{v} / \mathrm{v})$, and $47.8 \%(\mathrm{v} / \mathrm{v})$, respectively. The rice variety used in our experiment was japonica rice (Oryza sativa L. subsp. japonica Kato) Nanjing 46, which was transplanted with $13 \mathrm{~cm} \times 25 \mathrm{~cm}$ hill spacing on 26 and 28 June in 2015 and 2016, and harvested on 30 October and 4 November in 2015 and 2016, respectively.

Two irrigation treatments were designed for the experiment, FI and CI, and two fertilization treatments, CF or SR. The four treatments were flooding irrigation with conventional fertilization (FI-CF), flooding irrigation with straw returning (FI-SR), controlled irrigation with conventional fertilization (CI-CF), and controlled irrigation with straw returning (CI$\mathrm{SR})$. A randomized complete block design was established in 12 plots of $150 \mathrm{~m}^{2}(15 \mathrm{~m}$ length $\times 10 \mathrm{~m}$ width $)$ for the four treatments with three replicates. The ridges, $300 \mathrm{~mm}$ wide at the base and $200 \mathrm{~mm}$ high, were covered with a plastic membrane that was inserted into the soil plough layer to a depth of $300 \mathrm{~mm}$ on both sides of the ridges to isolate water in different plots and prevent hydraulic exchange between adjacent plots. 
For the FI treatment, a 3-5 cm standing water level was always maintained after transplanting (days after transplanting, DAT) except in the later tillering and yellow maturity stages. For the CI treatment, the water depth was maintained at 5-25 $\mathrm{mm}$ during the first 7-8 DAT in re-greening. At other stages, irrigation was applied to saturate the soil without flooding, except during the period of fertilization, herbicide, or pesticide application when 3-5 cm water was established in the rice field for 3-5 d. The maximum water depth after rainfall was set at $5 \mathrm{~cm}$ and maintained for less than $5 \mathrm{~d}$. The soil moisture thresholds for CI at different growth stages can be found in another document (Yang et al., 2018).

The rate and split applications of inorganic fertilizers followed the suggestions made by the local Agro-Technical Promotion Station, which provided detailed recommendations for fertilization and pest control based on local weather, soil fertility, and crop growth. The total N, P, and $\mathrm{K}$ inputs during the whole rice growth stage were $283.4 \mathrm{~kg} \mathrm{~N} \mathrm{ha}^{-1}$, $54.0 \mathrm{~kg} \mathrm{P}_{2} \mathrm{O}_{5} \mathrm{ha}^{-1}$, and $76.5 \mathrm{~kg} \mathrm{~K}_{2} \mathrm{O} \mathrm{ha}^{-1}$ in 2015 , respectively, while they were $321.1 \mathrm{~kg} \mathrm{~N}^{-1}, 45.0 \mathrm{~kg} \mathrm{P}_{2} \mathrm{O}_{5} \mathrm{ha}^{-1}$, and $63.8 \mathrm{~kg} \mathrm{~K}_{2} \mathrm{O}$ ha $^{-1}$ in 2016, respectively. Phosphorus and $\mathrm{K}$ compound fertilizers were applied as basal fertilization. The applied $\mathrm{N}$ fertilizers are listed in Table 1 . The basal fertilizers were mixed into the muddy soil and all other fertilizers were manually transferred to the surface water. In addition to chemical fertilizers, $3000 \mathrm{~kg} \mathrm{ha}^{-1}$ cut wheat straw was applied to the SR paddy fields in 2015 and 2016.

\section{Field measurements}

Irrigation water volumes were recorded with water meters installed on the pipes of each plot. Soil moisture was measured daily with three replicates using a time domain reflectometer (MiniTrase 6050X3, Soilmoisture Equipment Corp., SEC, Santa Barbara, California, USA) and $20 \mathrm{~cm}$ waveguides installed at $0-20 \mathrm{~cm}$ and $20-40 \mathrm{~cm}$ soil depth. Daily meteorological data (including precipitation volume, wind speed, temperature, sunshine duration, and relative humidity) were recorded with an automatic weather station (ICT International, Armidale, New South Wales, Australia). Ten rice plants in each plot were selected every $10 \mathrm{~d}$ during rice growth to measure plant height and number of tillers. Three rice plants in each plot at different growth stages were sampled to measure biomass. Rice yield was determined for each plot at harvest (30 October and 4 November in 2015 and 2016, respectively), $5 \times 6$ hills (holes) in each plot were selected to measure the number of panicles per unit area, number of spikelets per panicle, spikelet sterility or filled spikelet, thousand seed weight, and yield. Irrigation water use efficiency (IWUE) was calculated by dividing rice yield by irrigation water volume.

\section{Statistical analysis}

Two-way ANOVA analysis was performed to rank the factors (irrigation, SR, and the interaction between them) to determine rice growth, yield, or IWUE with SPSS19.0 software (SPSS Inc., Chicago, Illinois, USA). Fisher's least significant difference (LSD) test was used to detect the differences in rice growth and yield indices among treatments at $\mathrm{p}=0.05$.

Table 1. Nitrogen $(\mathrm{N})$ fertilizer management of rice in growth period.

\begin{tabular}{lcc}
\hline $\mathrm{N}$ fertilizer & 2015 & 2016 \\
\hline Base fertilizer & $\mathrm{kg} \mathrm{ha}^{-1}$ & $\mathrm{~kg} \mathrm{ha}^{-1}$ \\
& $(19 \mathrm{June})$ & $(28 \mathrm{June})$ \\
Tillering fertilizer & $69.3(\mathrm{U})$ & $97.0(\mathrm{U})$ \\
& $(5 \mathrm{July})$ & $(13 \mathrm{July})$ \\
Panicle fertilizer (9 and 3 August) & $58.9 \mathrm{U})$ & $104.0(\mathrm{U})$ \\
& $(9$ August $)$ & $(3$ August $)$ \\
Total N & 283.4 & 321.1 \\
\hline
\end{tabular}

Dates in brackets are the fertilization dates, respectively.

CF: Compound fertilizer $\left(\mathrm{N}, \mathrm{P}_{2} \mathrm{O}_{5}\right.$, and $\mathrm{K}_{2} \mathrm{O}$ contents are $16 \%, 12 \%$, and $17 \%$, respectively); AB: ammonium bicarbonate ( $17.1 \% \mathrm{~N}$ content); $\mathrm{U}$ : urea $(46.2 \% \mathrm{~N}$ content). 


\section{RESULTS}

\section{Rice plant height}

Plant height increased rapidly at the early and middle tillering stages (20-40 DAT) (Figure 1). It reached the highest value at the late jointing-booting stage or heading-flowering stage (approximately $80 \mathrm{DAT}$ ), and it was then stable until harvest. Throughout the observation period (15-125 DAT), rice plant height for CI-SR, CI-CF, FI-SR, and FI-CF fields were mainly within the following ranges: $35.6-96.6,34.8-93.6,35.1-97.9$, and $35.8-95.4 \mathrm{~cm}$ in 2015 , respectively, and $37.8-99.7,36.5-95.3,37.4-100.9$, and $37.9-99.3 \mathrm{~cm}$ in 2016 , respectively. It was clear that SR slightly promoted rice plant height compared with $\mathrm{CF}$, although CI slowed down crop growth and resulted in lower plant height compared with FI. When compared with FI-CF, CI-CF decreased the maximum plant height by $1.5 \%$ and $4.4 \%$, while CI-SR increased it by $1.7 \%$ and $0.8 \%$ in 2015 and 2016, respectively. This indicated that SR offset inhibition of rice plant growth caused by CI irrigation.

\section{Rice tillers}

The number of rice tillers was rapidly enhanced at the tillering stage and gradually decreased with the increasing number of non-effective tillers (Figure 2). The maximum number of tillers usually occurred at the late tillering or jointing stage (approximately $40 \mathrm{DAT}$ ). When compared with CF, SR increased the maximum number of rice tillers by $2.8 \%$ and $3.7 \%$ in 2015 and $5.1 \%$ and 5.6\% in 2016; it delayed peak time by 4 and $10 \mathrm{~d}$ and 5 and $5 \mathrm{~d}$ in the two seasons, respectively. In comparison with FI-CF, CI-CF decreased the maximum number of rice tillers by $2.4 \%$ and $4.1 \%$, while CI-SR enhanced it by $0.4 \%$ and $1.1 \%$ in 2015 and 2016, respectively. These results suggests that the fertility function of SR lagged behind the conventional fertilizer, which generally played a positive role after the middle tillering stage and led to an increase in the maximum number of rice tillers. However, for effective tillers, both CI-SR and CI-CF reduced them by $2.2 \%$ and $5.9 \%$ in 2015, and $2.1 \%$ and $5.8 \%$ in 2016, respectively, when compared with FI-CF. This indicates that SR could decrease non-effective tillers and improve effective tillers when compared with $\mathrm{CF}$, although it generally caused a lower effective tiller ratio.

\section{Biomass}

Rice biomass gradually increased over the growth period and showed a similar tendency among paddy fields with different water and fertilizer management (Figure 3). Biomass production increased more rapidly at the jointing stage (40-60 DAT) than at other stages, and reached its maximum at the milk ripening stage (approximately 90 DAT). The SR application increased biomass by $7.1 \%$ and $10.5 \%$ in 2015 and $10.0 \%$ and $11.1 \%$ in 2016, respectively, when compared

Figure 1. Variations in rice plant height during growth stages under different treatments.
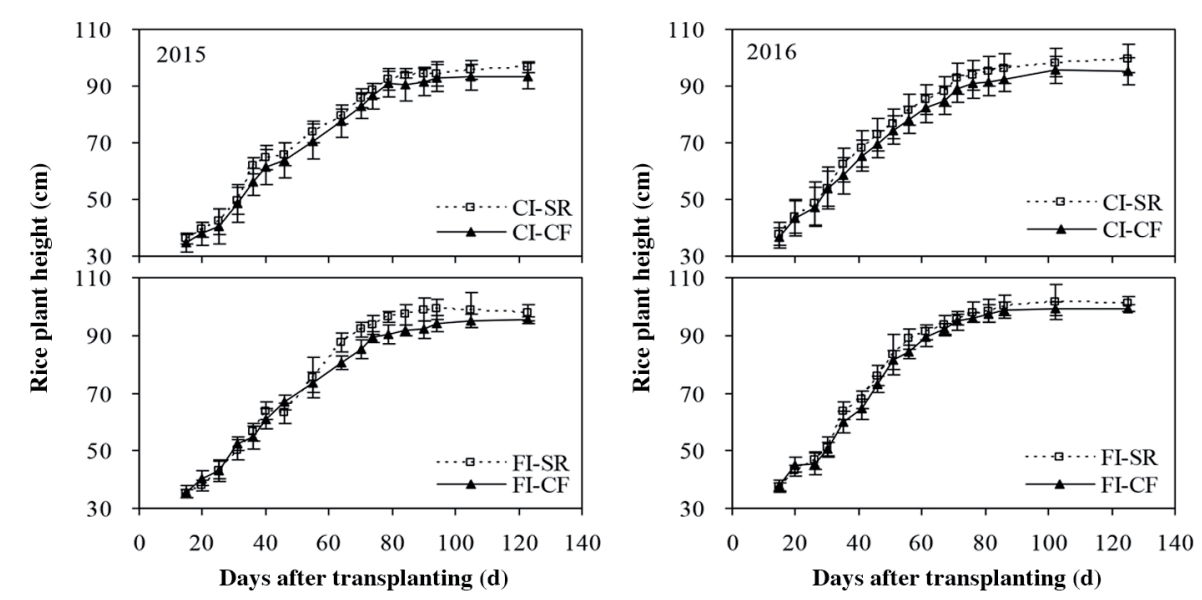

CI-CF: Controlled irrigation with conventional fertilization; CI-SR: controlled irrigation with straw returning; FI-CF: flooding irrigation with conventional fertilization; FI-SR: flooding irrigation with straw returning. 
Figure 2. Variations in the number of rice tillers during growth stages under different treatments.
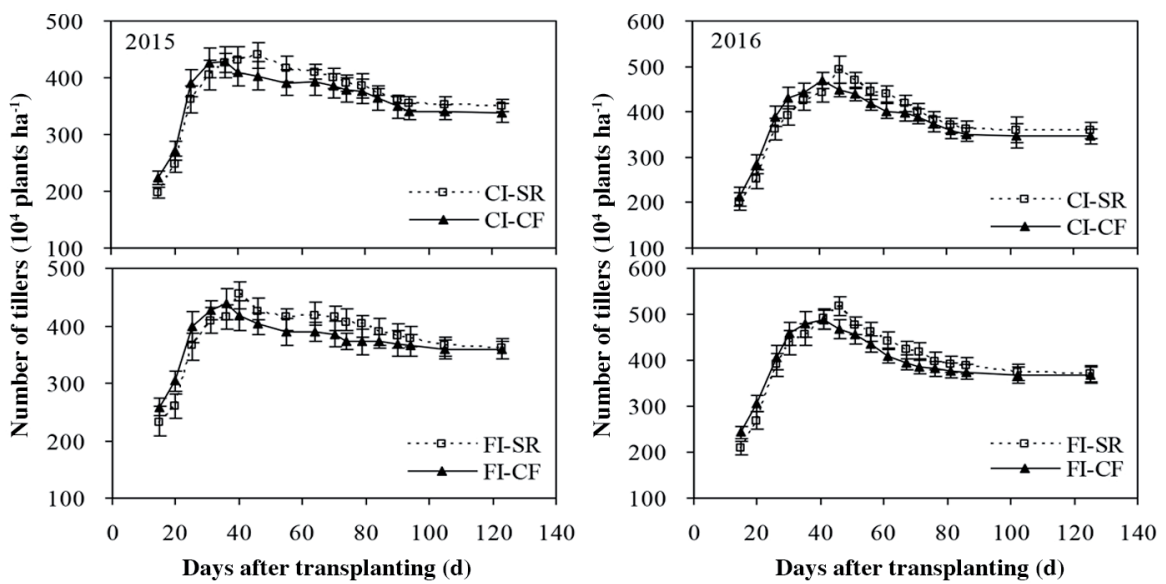

CI-CF: Controlled irrigation with conventional fertilization; CI-SR: controlled irrigation with straw returning; FI-CF: flooding irrigation with conventional fertilization; FI-SR: flooding irrigation with straw returning.

Figure 3. Variations in biomass during growth stages under different treatments.
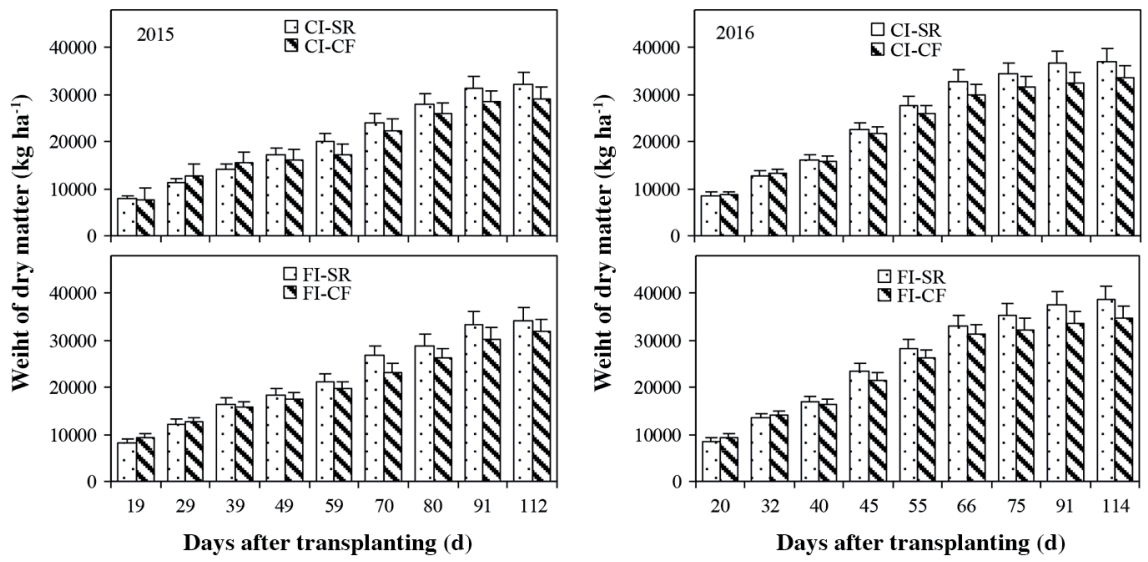

CI-CF: Controlled irrigation with conventional fertilization; CI-SR: controlled irrigation with straw returning;

FI-CF: flooding irrigation with conventional fertilization; FI-SR: flooding irrigation with straw returning.

with CF. Maximum biomass under CI was slightly lower and decreased on average by $5.8 \%$ and $3.6 \%$ in 2015 and 2016, respectively, when compared with FI. In comparison with FI-CF, CI-CF decreased maximum biomass by $8.6 \%$ and $3.1 \%$ while CI-SR increased it by $1.0 \%$ and $6.6 \%$ in 2015 and 2016, respectively. This reconfirmed the lag effect of SR fertilizer efficiency.

\section{Rice yield and water use efficiency}

There was nonsignificant difference in the ripening rate and thousand seed weight between paddy fields with or without SR application (Table 2). However, a significant increase was found in effective panicle for the paddy field with SR application. Rice yields in SR-applied paddy fields therefore increased by $7.9 \%$ and $7.9 \%$ and $7.1 \%$ and $8.7 \%$ and IWUE improved by $4.2 \%$ and $8.3 \%$ and $8.3 \%$ and $8.3 \%$ in 2015 and 2016, respectively. When compared with FI, rice yield from CI-irrigated paddy fields was almost the same, but IWUE significantly increased (95.3\% and $96.5 \%$ and $92.9 \%$ and $97.9 \%$ in 2015 and 2016, respectively) because the irrigation water volumes under CI were $49.2 \%$ and $49.5 \%$ and $49.2 \%$ and $49.8 \%$ lower $(\mathrm{p}<0.05)$ (Table 2$)$. 
Table 2. Rice yield and irrigation water use efficiency under different treatments.

\begin{tabular}{|c|c|c|c|c|c|c|c|c|c|}
\hline Year & Treatment & Yield & $\begin{array}{l}\text { Number of } \\
\text { panicles } \text { ha }^{-1}\end{array}$ & $\begin{array}{l}\text { Number of } \\
\text { spikelets per } \\
\text { spike }\end{array}$ & $\begin{array}{l}\text { Ripening } \\
\text { rate }\end{array}$ & $\begin{array}{l}\text { Thousand } \\
\text { seed weight }\end{array}$ & $\begin{array}{c}\text { Irrigation } \\
\text { volume }\end{array}$ & IWUE & $\begin{array}{c}\text { Rice } \\
\text { biomass }\end{array}$ \\
\hline \multirow{5}{*}{2015} & & $\mathrm{~kg} \mathrm{ha}^{-1}$ & & & $\%$ & $\mathrm{~g}$ & $\mathrm{~mm}$ & $\mathrm{~kg} \mathrm{~m}^{-3}$ & $\mathrm{~kg} \mathrm{ha}^{-1}$ \\
\hline & CI-SR & $10347.2 \pm 107.2 \mathrm{a}$ & $3744087.1 \pm 22221.4 b$ & $124.6 \pm 1.1 \mathrm{a}$ & $83.5 \pm 3.6 \mathrm{a}$ & $27.4 \pm 1.1 \mathrm{a}$ & $411.3 \pm 4.7 b$ & $2.5 \pm 0.02 \mathrm{a}$ & $31461.6 \pm 2354.7 \mathrm{a}$ \\
\hline & CI-CF & $9588.9 \pm 88.2 b$ & $3516256.5 \pm 19339.2 c$ & $122.3 \pm 1.3 \mathrm{a}$ & $82.0 \pm 4.4 \mathrm{a}$ & $27.1 \pm 1.2 \mathrm{a}$ & $406.5 \pm 5.5 b$ & $2.4 \pm 0.02 b$ & $29453.8 \pm 2456.6 \mathrm{a}$ \\
\hline & FI-SR & $10422.1 \pm 105.9 \mathrm{a}$ & $3864478.5 \pm 15501.2 \mathrm{a}$ & $126.5 \pm 1.5 \mathrm{a}$ & $81.6 \pm 4.5 \mathrm{a}$ & $27.6 \pm 1.4 \mathrm{a}$ & $809.1 \pm 9.7 \mathrm{a}$ & $1.3 \pm 0.02 \mathrm{c}$ & $32371.7 \pm 2628.7 \mathrm{a}$ \\
\hline & FI-CF & $9657.2 \pm 54.4 \mathrm{~b}$ & $3768579.0 \pm 16563.1 \mathrm{~b}$ & $124.1 \pm 1.0 \mathrm{a}$ & $79.0 \pm 4.6 \mathrm{a}$ & $27.4 \pm 1.8 \mathrm{a}$ & $804.3 \pm 9.3 \mathrm{a}$ & $1.2 \pm 0.01 \mathrm{~d}$ & $30338.9 \pm 2436.5 \mathrm{a}$ \\
\hline \multirow[t]{4}{*}{2016} & CI-SR & $10408.1 \pm 104.2 \mathrm{a}$ & $3696405.2 \pm 20571.5 b$ & $125.2 \pm 1.4 \mathrm{a}$ & $83.1 \pm 3.7 \mathrm{a}$ & $28.2 \pm 1.4 \mathrm{a}$ & $401.2 \pm 5.1 \mathrm{~b}$ & $2.6 \pm 0.02 \mathrm{a}$ & $39073.0 \pm 2672.4 \mathrm{a}$ \\
\hline & $\mathrm{CI}-\mathrm{CF}$ & $9576.0 \pm 82.9 \mathrm{~b}$ & $3504520.3 \pm 19057.6 \mathrm{c}$ & $123.4 \pm 1.2 \mathrm{a}$ & $82.4 \pm 4.2 \mathrm{a}$ & $27.4 \pm 1.2 \mathrm{a}$ & $408.7 \pm 4.6 \mathrm{~b}$ & $2.3 \pm 0.03 b$ & $38692.3 \pm 2255.3 a$ \\
\hline & FI-SR & $10479.0 \pm 107.3 \mathrm{a}$ & $3856846.5 \pm 18135.2 \mathrm{a}$ & $127.2 \pm 1.7 \mathrm{a}$ & $81.3 \pm 4.0 \mathrm{a}$ & $27.7 \pm 1.1 \mathrm{a}$ & $799.2 \pm 9.6 \mathrm{a}$ & $1.3 \pm 0.02 \mathrm{c}$ & $26652.9 \pm 1789.0 \mathrm{~b}$ \\
\hline & FI-CF & $9782.3 \pm 66.2 b$ & $3752686.2 \pm 19687.7 \mathrm{~b}$ & $124.8 \pm 1.5 \mathrm{a}$ & $79.2 \pm 3.5 \mathrm{a}$ & $28.1 \pm 1.3 \mathrm{a}$ & $805.2 \pm 8.3 \mathrm{a}$ & $1.2 \pm 0.01 \mathrm{~d}$ & $39781.7 \pm 2731.9 \mathrm{a}$ \\
\hline
\end{tabular}

CI-CF: Controlled irrigation with conventional fertilization; CI-SR: controlled irrigation with straw returning; FI-CF: flooding irrigation with conventional fertilization; FI-SR: flooding irrigation with straw returning; IWUE: Irrigation water use efficiency.

Different lowercase letters in the same column indicate significant differences $(\mathrm{p}=0.05)$.

\section{DISCUSSION}

Straw is an important source of organic fertilizer, which usually affects the $\mathrm{C}$ and $\mathrm{N}$ cycle in the agro-ecosystem, and thus crop growth and yield (Singh, 2003; Thuy et al., 2008; Liu et al., 2014b). The present study indicated that SR slightly inhibited rice growth (plant height, number of tillers, and biomass production) during the first $20 \mathrm{~d}$ of the rice season, while it clearly improved after the late tillering or jointing stage (approximately 40 DAT) (Figures 1, 2, and 3). This concurs with other studies found in the literature (Sun et al., 2012; Fang, 2017). For example, Sun et al. (2012) have indicated nonsignificant differences in rice growth and biomass at the jointing stage between paddy fields with and without SR, but found differences during the ripening stage. Fang (2017) have demonstrated that rice plant height and number of tillers are lower in fields with SR than those without SR at the early growth stage; however, these clearly improved at the late growth stage. These results imply the need for a period before the straw nutrients are available for rice growth. Generally, at the initial stage after straw application, some soil available $\mathrm{N}$ is fixed by soil microorganisms due to high straw $\mathrm{C} / \mathrm{N}$ ratio. This leads to an insufficient $\mathrm{N}$ supply at the seedling stage and thus inhibits rice growth (number of tillers, plant height, and biomass) (Thuy et al., 2008; Jin et al., 2013; Fu et al., 2013). However, there are more available soil nutrients with straw fermentation, which may accelerate rice growth (Singh, 2003; Han et al., 2012; Liu, 2012). In the present study, the maximum plant height, number of tillers, and biomass production at harvest improved in paddy fields with SR compared with those without SR (Figures 1,2, and 3). This suggests that the SR promotion effect on rice growth is generally greater than its inhibition effect throughout the rice season.

Rice yields in paddy fields usually improve with SR (Xu et al., 2009; Li et al., 2009); however, there is still no consistent conclusion about the mechanism to increase yield with SR. For example, Xu et al. (2009) have found that SR enhanced rice yield by improving rice panicles ha ${ }^{-1}$, ripening rate, and thousand seed weight. On the other hand, Li et al. (2009) have indicated that only improving rice panicles ha $^{-1}$ was the key factor for increasing rice yield. In the present study, rice panicles ha-1 and yield significantly increased in paddy fields with SR application compared with those without SR application, while spikelets per spike, ripening rate, and thousand seed weight were not significantly different (Table 2). Two-way ANOVA also indicated that the effects of SR were significant for rice panicles ha ${ }^{-1}$ and yield. Thus, it can be inferred that increased rice panicles ha-1 may be the reason for enhanced rice yield in SR-applied paddy fields.

Previous studies have investigated the interaction effect of SR and tillage, fertilization on rice growth, and yield under FI (Mohanty et al., 2007; Pooniya and Shivay, 2012; Yadav et al., 2018; Kubar et al., 2018), but very little research has focused on the interaction effect of irrigation regimes (FI and CI) and SR on rice growth and yield (Yang et al., 2018). In the present study, two-way ANOVA analysis indicated that the effects of irrigation or SR were significant for rice growth, yield, and IWUE, while their interaction effects were nonsignificant for most of these indices (Table 3). As for rice maximum plant height and biomass at harvest, the SR effect was greater than for irrigation and was significant for rice biomass in 2016. However, the number of tillers at harvest was different and the SR effect was lower than for irrigation. Regarding yield and its components, rice spikelets per spike and yield showed a closer response to SR than irrigation, and 
Table 3. Two-way ANOVA results for rice growth, yield, and irrigation water use efficiency (IWUE).

\begin{tabular}{|c|c|c|c|c|c|c|c|c|}
\hline & & & & 2015 & & & 2016 & \\
\hline & Item & & I & $\mathrm{S}$ & $\mathrm{I} * \mathrm{~S}$ & I & $\mathrm{S}$ & $\mathrm{I} * \mathrm{~S}$ \\
\hline Rice growth & Maximum plant height & SS & 7.4 & 22.9 & 0.2 & 20.3 & 27.6 & 5.6 \\
\hline & & $\mathrm{F}$ & 0.9 & 2.9 & 0 & 5 & 6.7 & 1.4 \\
\hline & & $\mathrm{P}$ & 0.364 & 0.129 & 0.877 & 0.057 & $0.032 *$ & 0.275 \\
\hline & Tillers at harvest & SS & 736.9 & 185.5 & 94.5 & 755 & 190.6 & 96.2 \\
\hline & & $\mathrm{F}$ & 3.2 & 0.8 & 0.4 & 2.6 & 0.7 & 0.3 \\
\hline & & $\mathrm{P}$ & 0.113 & 0.398 & 0.542 & 0.143 & 0.438 & 0.578 \\
\hline & Biomass at harvest & SS & $2.4 \times 10^{6}$ & $12.2 \times 10^{6}$ & 468.8 & $96.3 \times 10^{6}$ & $121.9 \times 10^{6}$ & $136.9 \times 10^{6}$ \\
\hline & & $\mathrm{F}$ & 0.4 & 1.9 & 0 & 14.3 & 18.1 & 20.3 \\
\hline & & $\mathrm{P}$ & 0.553 & 0.201 & 0.993 & $0.005^{*}$ & $0.003 *$ & $0.002 *$ \\
\hline Rice yield & Number of panicles ha-1 & SS & $4.6 \times 10^{8}$ & $3.5 \times 10^{8}$ & $0.6 \times 10^{8}$ & $1252.2 \times 10^{8}$ & $657.3 \times 10^{8}$ & $57.7 \times 10^{8}$ \\
\hline & & $\mathrm{F}$ & 301.5 & 227.4 & 37.8 & 333.3 & 175 & 15.4 \\
\hline & & $\mathrm{P}$ & $0.000 *$ & $0.000 *$ & $0.000 *$ & $0.000^{*}$ & $0.000 *$ & $0.004 *$ \\
\hline & Number of spikelets per spike & SS & 10.3 & 16.6 & 0 & 8.7 & 13.2 & 0.3 \\
\hline & & $\mathrm{F}$ & 6.7 & 10.8 & 0 & 4.1 & 6.2 & 0.1 \\
\hline & & $\mathrm{P}$ & $0.032 *$ & $0.011 *$ & 0.946 & 0.079 & $0.038 *$ & 0.731 \\
\hline & Ripening rate & SS & 18 & 12.6 & 0.9 & 18.7 & 5.9 & 1.5 \\
\hline & & $\mathrm{F}$ & 0.9 & 0.6 & 0 & 1.3 & 0.4 & 0.1 \\
\hline & & $P$ & 0.366 & 0.446 & 0.835 & 0.294 & 0.547 & 0.761 \\
\hline & Thousand seed weight & SS & 1.3 & 0.2 & 0.1 & 0 & 0.2 & 0.1 \\
\hline & & $\mathrm{F}$ & 3.4 & 0.5 & 0.2 & 0 & 0.8 & 0.4 \\
\hline & & $P$ & 0.103 & 0.500 & 0.683 & 0.829 & 0.399 & 0.523 \\
\hline & Yield & SS & $1.5 \times 10^{4}$ & $174.0 \times 10^{4}$ & 32.7 & $5.7 \times 10^{4}$ & $175.3 \times 10^{4}$ & $1.4 \times 10^{4}$ \\
\hline & & $\mathrm{F}$ & 1.8 & 208.1 & 0 & 6.9 & 208.5 & 1.6 \\
\hline & & $\mathrm{P}$ & 0.212 & $0.000 *$ & 0.952 & $0.031 *$ & 0.000* & 0.237 \\
\hline & IWUE & SS & 4.3 & 0 & 0 & 4.3 & 0.1 & 0 \\
\hline & & $\mathrm{F}$ & 13292.3 & 92.3 & 0 & 9600 & 266.7 & 66.7 \\
\hline & & $\mathrm{P}$ & 0.000* & $0.000 *$ & 1.000 & 0.000* & 0.000* & $0.000 *$ \\
\hline
\end{tabular}

* Significant at $\mathrm{p}=0.05$.

I: Irrigation; S: straw returning; I*S: effect of irrigation and straw returning interaction; SS: sum of squares of mean deviation.

the effects of SR were significant for these two indices. As for rice panicles ha- ${ }^{-1}$ and IWUE, both the effects of SR and irrigation were significant. As a consequence, the interactive effect of irrigation and SR was significant in both years for rice panicles ha $^{-1}$, but only in 2016 for rice biomass, yield, and IWUE.

Irrigation and SR are two important factors that affect rice growth and yield (Ravisankar et al., 2014; Li et al., 2016; Kaur and Mahal, 2017; Yang et al., 2018). The present study indicated that CI delayed the peak time of rice tillering and decreased plant height, number of tillers, and yield compared with FI. On the other hand, SR enhanced the maximum plant height, number of tillers, biomass production, and yield compared with those without SR application. The CI-SR combination significantly enhanced plant height, number of tillers, biomass, and yield compared with FI-CF. Since these indices were lower in CI than in FI irrigated fields (Table 2), this indicates that SR may provide some 'buffering' against the inhibition effect of $\mathrm{CI}$ on rice growth and yield. Moreover, the significantly reduced irrigation volume and improved yield in the CI-SR field resulted in a significantly higher IWUE for CI-SR; it should therefore be an effective measure for enhancing soil fertility, maintaining the rice field, and increasing IWUE.

Although there is a contradiction between improved rice yield and inhibited plant growth in the early growth stage, this likely indicates that there are still some inadequacies in the combined management of SR and chemical fertilizer for paddy fields. Thus, diverting some top-dressed chemical fertilizer to basal application may be a potential measure to mitigate SR inhibition on rice growth at the early growth stage while also meeting crop nutrient uptakes. The requirement may be more necessary for CI than FI. 


\section{CONCLUSIONS}

The present study investigated rice growth and yield as affected by straw returning (SR) under water-saving irrigation (WSI). Results indicated that SR could offset the WSI-driven reduction in soil organic C content of paddy fields and was helpful for producing large rice panicles and increasing effective panicles and yield. The combined application of SR and controlled irrigation (CI) could maintain high rice yield and significantly increase irrigation water use efficiency (IWUE) of paddy fields: it should be an effective measure to achieve sustainable water and fertilizer utilization in paddy fields. Slow rice growth at the early stage, delayed tillering time, and low effective tiller ratio indicated that increasing chemical fertilizer at the basal fertilizer application stage could mitigate SR inhibition on crop growth in the early growth stage, while also meeting crop nutrient uptakes, especially for CI.

\section{ACKNOWLEDGEMENTS}

Financial support for this research was provided by the National Science Foundation of China (51809077; 51879075; 51809075), China Postdoctoral Science Foundation (2017M621620), Postdoctoral Research funding scheme in Jiangsu Province (2018K122C), and the Fundamental Research Funds for the Central Universities (2018B56014; 2018B00414).

\section{REFERENCES}

Abrantes, J.R.C.B., Prats, S.A., Keizer, J.J., and de Lima, J.L.M.P. 2018. Effectiveness of the application of rice straw mulching strips in reducing runoff and soil loss: Laboratory soil flume experiments under simulated rainfall. Soil and Tillage Research 180:238-249.

Asten, P., Bodegom, P., Mulder, L., and Kropff, M. 2005. Effect of straw application on rice yields and nutrient availability on an alkaline and a pH-neutral soil in a Sahelian irrigation scheme. Nutrient Cycling in Agroecosystems 72:255-266.

Beutler, A.N., Ferreira, M.M., Zambeli, M., and Galon, L. 2017. Performance of flood-irrigated rice as affected by residual rice straw. Pesquisa Agropecuária Tropical 47:246-252.

Bouman, B.A.M., Lampayan, R.M., and Tuong, T.P. 2007. Water management in irrigated rice: coping with water scarcity. International Rice Research Institute (IRRI), Los Baños, Philippines.

Curtin, D., and Fraser, P.M. 2003. Soil organic matter as influenced by straw management practices and inclusion of grass and clover seed crops in cereal rotations. Australian Journal of Soil Research 41:95-106.

Fang, F.F. 2017. Study on the effect of wheat straw returning to the field on the early growth of rice and its mechanism. 44 p. MSc. thesis. Yangzhou University, College of Agriculture, Jiang Su, China.

Fu, M.Y., Zhu, L.Q., Li, Y., and Bian, X.M. 2013. Effects of straw concentration and deep embedding on rice growth and yield. Jiangsu Agricultural Sciences 41:67-69.

Ge, L.L., Ma, Y.H., Bian, J.L., Wang, Z.Q., Yang, J.C., and Liu, L.J. 2013. Effects of returning maize straw to field and sitespecific nitrogen management on grain yield and quality in rice. Chinese Journal of Rice Science 27:153-160.

Han, X.Z., Zhu, L.Q., Yang, M.F., Yu, Q., and Bian, X.M. 2012. Effect of different amount of wheat straw returning on rice growth, soil microbial biomass and enzyme. Journal of Agro-Environment Sciences 11:2192-2199.

Jin, X., Cai, L.Y., Li., G.H., Hou, P.F., and Wang, S.H. 2013. Effects of all wheat crop straw application on rice growth and redox substance in rice fields. Soils and Fertilizers Sciences in China 5:80-85.

Kaur, J., and Mahal, S.S. 2017. Influence of paddy straw mulch on crop productivity and economics of bed and flat sown wheat (Triticum aestivum) under different irrigation schedules. Journal of Environmental Biology 38:243-250.

Kubar, K.A., Huang, L., Lu, J., Li, X., Xue, B., and Yin, Z. 2018. Integrative effects of no-tillage and straw returning on soil organic carbon and water stable aggregation under rice-rape rotation. Chilean Journal of Agricultural Research 78:205-215.

Lal, R. 2005. World crop residues production and implications of its use as a biofuel. Environment International 31:575-584.

Li, Y., Cao, H.D., Deng, J.S., Zhu, R.S., Bai, J.R., and Zhou, H. 2009. Effects of return of total wheat straw on soil mineral nitrogen dynamics and rice yield. Journal of Ecology and Rural Environment 25:46-51.

Li, Z.C., Xu, X.W., Pan, G.X., Smith, P., and Cheng, K. 2016. Irrigation regime affected SOC content rather than plow layer thickness of rice paddies: A county level survey from a river basin in lower Yangtze valley, China. Agricultural Water Management 172:31-39. 
Liu, M. 2012. Nutrient release characteristics of wheat straw and effect of entire wheat straw returning on rice yield and soil fertility. 52 p. MSc. thesis. Yangzhou University, College of Agriculture, Jiang Su, China.

Liu, S.L., Huang, D.Y., Chen, A., Wei, W., Brookes, P.C., Li, Y., et al. 2014b. Differential responses of crop yields and soil organic carbon stock to fertilization and rice straw incorporation in three cropping systems in the subtropics. Agriculture Ecosystems and Environment 184:51-58.

Liu, Y.C., Zeng, X.Z., Feng, W.Q., Qin, Y.S., Wang, C.Q., Tu, S.H., et al. 2014a. Effects of long-term straw mulch and fertilization on crop yields and soil physical and chemical properties under rice-rapeseed rotation. Journal of Plant Nutrition and Fertilizer 20:1450-1459.

Mi, W.H., Sun, Y., Xia, S.Q., Zhao, H.T., Mi, W.T., Brookes, P.C., et al. 2018. Effect of inorganic fertilizers with organic amendments on soil chemical properties and rice yield in a low-productivity paddy soil. Geoderma 320:23-29.

Mohanty, M., Painuli, D.K., Misra, A.K., and Ghosh, P.K. 2007. Soil quality effects of tillage and residue under rice-wheat cropping on a Vertisol in India. Soil and Tillage Research 92:243-250.

Pooniya, V., and Shivay, Y.S. 2012. Summer green-manuring crops and zinc fertilization on productivity and economics of basmati rice (Oryza sativa L.) Archives of Agronomy and Soil Science 58:593-616.

Ravisankar, N., Balakrishnan, M., Ambast, S.K., Srivastava, R.C., Bommayasamy, N., and Subramani, T. 2014. Influence of irrigation and crop residue mulching of yield and water productivity of table purpose groundnut (Arachis hypogaea) in humid tropical island. Legume Research 37:195-200.

Sfez, S., De Meester, S., and Dewulf, J. 2017. Co-digestion of rice straw and cow dung to supply cooking fuel and fertilizers in rural India: Impact on human health, resource flows and climate change. Science of the Total Environment 609:1600-1615.

Singh, Y. 2003. Crop residue management in rice-wheat system. p. 153-156. Addressing resource conservation issues in ricewheat systems of South Asia: A resource book. Rice-Wheat Consortium for the Indo-Gangetic Plains-International Maize and Wheat Improvement Center (RWC-CIMMYT), New Delhi, India.

Sun, Y., Liu, Y.L., Xiao, W.H., Fan, L.L., Zhou, Y.H., Leng, L.L., et al. 2012. Effects of rice straw application to soda-salinization paddy soil on rice growth and grain yield. Crops 4:49-52.

Thuy, N.H., Shan, Y.H., Singh, B.J., Wang, K.R., Cai, Z.C., Singh, Y., et al. 2008. Nitrogen supply in rice-based cropping systems as affected by crop residue management. Soil Science Society of America Journal 72:514-523.

Wang, X.J., Jia, Z.K., Liang, L.Y., Zhao, Y.F., Yang, B.P., Ding, R.X., et al. 2018. Changes in soil characteristics and maize yield under straw returning system in dryland farming. Field Crops Research 218:11-17.

Xu, K., Liu, M., Chen, J.D., Gu, H.Y., Dai, Q.G., Ma, K.Q., et al. 2015. Effects of wheat-straw returning into paddy soil on dissolved organic carbon contents and rice grain yield. Chinese Journal of Applied Ecology 26(2):430.

Xu, G.W., Tan, G.L., Wang, Z.Q., Liu, L.J., and Yang, J.C. 2009. Effects of wheat-residue application and site-specific nitrogen management on grain yield and quality and nitrogen use efficiency in direct-seeding rice. Scientia Agricultura Sinica 42:2736-2746.

Xu, J., Yu, Z., Shi, Y., Guo, P., and Wang, Y. 2017. Effect of different supplemental irrigation strategies on photosynthetic characteristics and water use efficiency of wheat. Chilean Journal of Agricultural Research 77:346-354.

Yadav, G.S., Das, A., Lal, R., Babu, S., Meena, R.S., Patil, S.B., et al. 2018. Conservation tillage and mulching effects on the adaptive capacity of direct-seeded upland rice (Oryza sativa L.) to alleviate weed and moisture stresses in the North Eastern Himalayan Region of India. Archives of Agronomy and Soil Science 64:1254-1267.

Yang, Y.R., Wang, X.X., Zhang, T.L., and Li. D.C. 2014. Utilization of crop straw resources in Anhui Province, Eastern China. Bulgarian Journal of Agricultural Science 20:1302-1310.

Yang, S.H., Xiao, Y.N., Xu, J.Z., and Liu, X.Y. 2018. Effect of straw return on soil respiration and NEE of paddy fields under water-saving irrigation. PLOS ONE 13:e0204597.

Zhang, X.Q., Qian, Y.L., and Cao, C.F. 2015. Effects of straw mulching on maize photosynthetic characteristics and rhizosphere soil micro-ecological environment. Chilean Journal of Agricultural Research 75:481-487.

Zhang, W.Y., Zhu, L.Q., Wang, W., Zhang, Z.W., and Bian, X.M. 2014. Effect of wheat straw returning under different irrigation methods on rice growth. Crops 2:113-118.

Zhao, J.H. 2016. Effects of water-nitrogen management and straw returning on the growth of rice and physical and chemical properties of paddy soil in ditch under no-tillage. MSc. Thesis. Sichuan Agricultural University, Sichuan, China.

Zhao, H.L., Wang, Q., Sun, Y., Zeng, X.N., Zhang, X.M., Wang, P., et al. 2018. Effect of different irrigation regimes on rice yield and water use efficiency under straw returning to field. Journal of Nuclear Agricultural Sciences 32:0959-0969. 